\title{
新高保磁力 $\mathrm{Cu}-\mathrm{Mn}-\mathrm{Sb}$ 系合金の磁性についで
}

增 本 量** 渡辺清**

Hakaru Masumoto and Kiyoshi Watanabe : Magnetic Properties of New High Coercivity $\mathrm{Cu}-\mathrm{Mn}-\mathrm{Sb}$ Alloys. Magnetic properties of $\mathrm{Cu}-\mathrm{Mn}-\mathrm{Sb}$ alloys containing $4.98 \sim 59.80 \%$ of $\mathrm{Mn}$ and $10.03 \sim 79.71 \%$ of $\mathrm{Sb}$ have been measured. It has been found that the alloys consisting of about $17 \sim 40 \% \mathrm{Mn}, 10 \sim 54 \% \mathrm{Sb}$ and $9 \sim 65 \% \mathrm{Cu}$ show high coercive forces when tempered at $150^{\circ} \sim$ $650^{\circ} \mathrm{C}$ after chill casting and the alloy consisting of $22.04 \% \mathrm{Mn}, 33.00 \% \mathrm{Sb}$ and the rest $\mathrm{Cu}$ exhibits the highest coercive force, ${ }_{I} H_{C}$, of 20000 and a residual intensity of magnetization, $I_{r}$, of $12 \mathrm{G}$. Further it has been determined by means of electron microscopic observation and $\mathrm{X}$-ray analysis that these alloys of high coercive force contain many acicular fine particles of ferrimagnetic compound $\mathrm{Mn}_{2} \mathrm{Sb}$ dispersed in the matrices of nonmagnetic compound $\mathrm{CuMnSb}$ and nonmagnetic $\alpha_{\mathrm{Cu}}$ phase. The high coercivity of these alloys is probably caused by the anisotropy energy of these small particles composed of a single magnetic domain.

(Received June 2, 1969)

\section{I.}

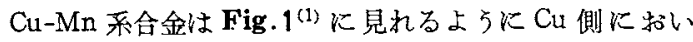
てほぼ $-60^{\circ} \mathrm{C}$ を極大とするCurie 点を有し，常温より液 体窒素温度まで磁場冷却すると，いわ的る交換磁気異方性 により移動ヒステリシスループを示し，一方向に高保磁力 を発揮する特殊な現象(2)を示するのとして知られている。 $\mathrm{Mn}-\mathrm{Sb}$ 系合金には Fig.2 ${ }^{(3)}$ に示すように, フェり磁性の $\mathrm{Mn}_{2} \mathrm{Sb}$ 化合物福よび強磁性の $\mathrm{MnSb}$ 化合物が存在し，その 保磁力 ${ }_{B} H_{C}{ }^{(4)}$ は非常に小さく，それぞれ僅か 31 と $80 \mathrm{e}$

** 財団法人電気磁気材料研究所 (Foundation: The Research Institute of Electric and Magnetic Alloys, Sendai)

* 1966 年 10 月本会尼崎大会および 1967 年 4 月本会東 京大会に発表; 財団法人電気磁気材料研究所研究報 告第 38 号

(1) E. Scheil and E. Wachtel : Z. Metallk., 48(1957), 571.

(2) J.S.Kouvel : J.Phys. Chem.Solids, 21 (1961), 57.

(3) M. Hansen : Constitution of Binary Alloys, M.M.E. Serves, 2 nd Edit.,(1958), 950.
示すにすぎない。また $\mathrm{Cu}-\mathrm{Sb}$ 系合金には $\mathrm{Cu}$ 側に二つの非 磁性化合物と種々な非磁性相が存在して扔る。つぎに Cu$\mathrm{Mn}-\mathrm{Sb} 3$ 元合金については, 強磁性 $\mathrm{Cu}_{2} \mathrm{MnSb}{ }^{(5)}$ 抢よび常 磁性 $\mathrm{CuMnSb}^{(6)(7)}$ の二つの化合物が第ると報告されておっ たが，前者については Oxley ら ${ }^{(8)}$ がさらに研究を行ない， この化合物忙反強磁性であると報告し，また最近では

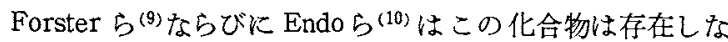
いと結論して扔る。しかし $\mathrm{Cu}-\mathrm{Mn}-\mathrm{Sb} 3$ 元合金の広い組成

(4) E. Wedekind : Trans.Faraday Soc., 8(1912), 160.

(5) F. Heusler, W. Stark and E. Haupt: Verhandl. Deut.Physik Ges., 5(1903), 220.

(6) H.Nowotny und B.Glatzl: Mh.Chem., 83 (1952), 237.

(7) L.Castelliz: Mh.Chem., 83(1952), 1314.

(8) D. P. Oxley, R. S. Tebble, C. T. Slach and K.C. Williams : Nature, $197(1962), 465 ;$ D. P. Oxley, R.S. Tebble and K.C.Williams : J.Appl. Phys., 34 (1963), 1362.

(9) R.H. Forster, G.B. Johnston and D.A.Wheeler : J.Phys.Chem. Solids, 29(1968), 855.

(10) K.Endo, T. Ohoyama and R.Kimura: J.Phys. Soc. Japan, 25(1968), 907. 
範囲については，従来その研究がないので，著者らはこの 3 元合金について広く組成を変えてその磁気特性を測定し た.

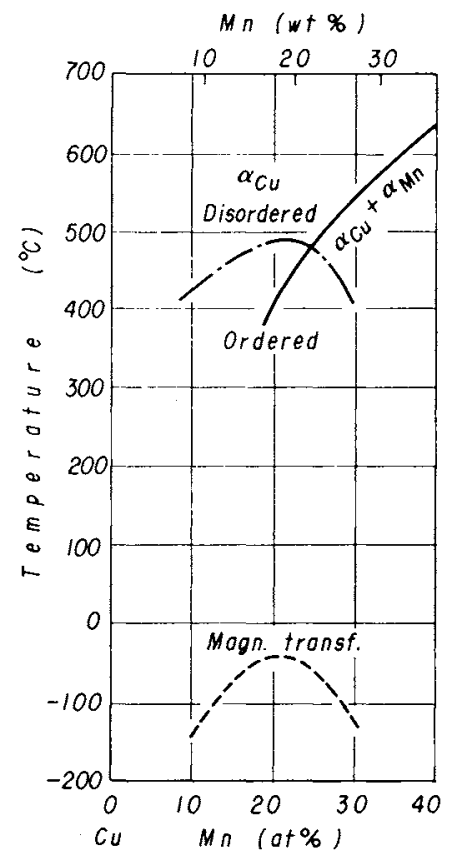

Fig.1 Equilibrium diagram of $\mathrm{Cu}-\mathrm{Mn}$ alloys

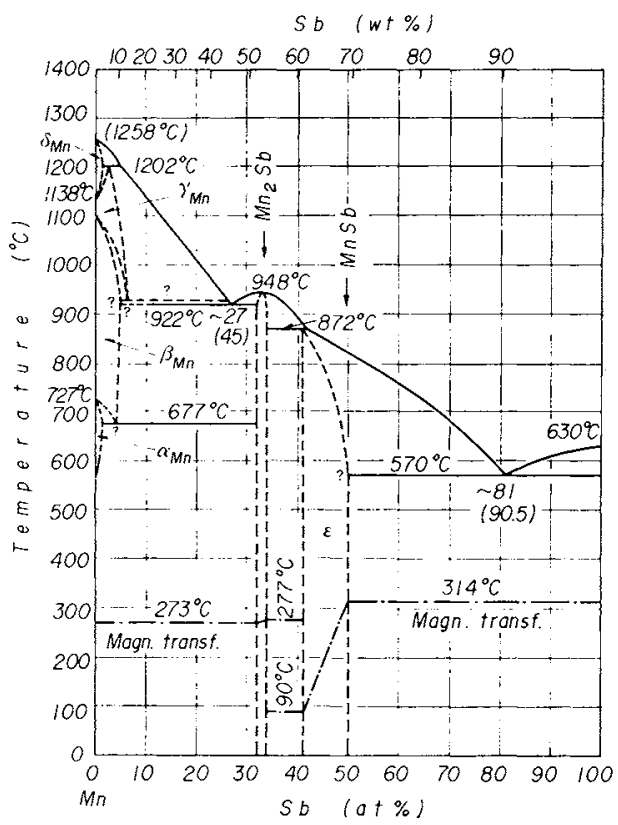

Fig.2 Equilibrium diagram of $\mathrm{Mn}-\mathrm{Sb}$ alloys

\section{II. 試料ならびに実験方法}

合金の原料は純度 $99.9 \%$ C と純度 $99.84 \%$ Mn 扣よび純度 $99.999 \%$ Sbであった。試料を造るにはまず $\mathrm{Sb}$ をアルミナ坩堝中でフルゴンを通じながら Tammann
炉を用いて溶かし，その中に Mn 括よび Cu を投入してよ く翼拌して均質な溶融合金を造った。つぎにこれを内径 $4 \mathrm{~mm}$ 外径 $47 \mathrm{~mm}$ の銅型に鋳込んで急冷した. そしてその 丸棒の中央から長さ $20 \mathrm{~mm}$ ののを切りとって試料とし た。試料の数は 68 種類で組成は Mn 4.98 から $59.80 \%$ ， Sb 10.03 から $79.71 \%$ 执よび Cu残余の範囘に亘ってい る.

試料を焼鈍するには，これを真空炉中に扎いて $550^{\circ} \mathrm{Cか}$ ら $800^{\circ} \mathrm{C}$ の温度で $5 \sim 50 \mathrm{hr}$ 加熱した後, $50^{\circ} \mathrm{C} / \mathrm{hr}$ から 300 ${ }^{\circ} \mathrm{C} / \mathrm{hr}$ の速度で徐冷した．また試料を焼戻しするには，移 動可能な電気炉を用い，試料を空気中あるい慎空中で $150^{\circ} \mathrm{C}$ か $560^{\circ} \mathrm{C}$ の温度に $30 \mathrm{~min} \sim 100 \mathrm{hr}$ 加熱した後, 空 冷するかあるいは電気炉を移動させて急冷した。

磁性の测定は，電磁石，磁束計，自動磁束記録装置およ び磁気天科記録装置により最高 22000 De までの磁場中で 行なった。 な 線結晶構造解析は Debye-Scherrer 法㐫 るいは Diff ractometer 浩によって行なった。

\section{III. 実験結果ならびに考察}

銅型に鋳込んで急冷したままの状態における合金の飽和 磁東密度 $4 \pi I_{s}$ と組成との臂係は等便曲線として Fig.3

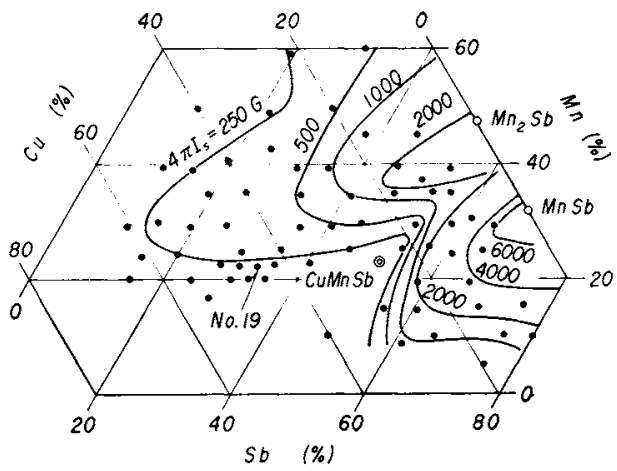

Fig.3 Saturation intrinsic magnetic flux density $4 \pi I_{s}$ of $\mathrm{Cu}-\mathrm{Mn}-\mathrm{Sb}$ alloys as chill cast into copper mold

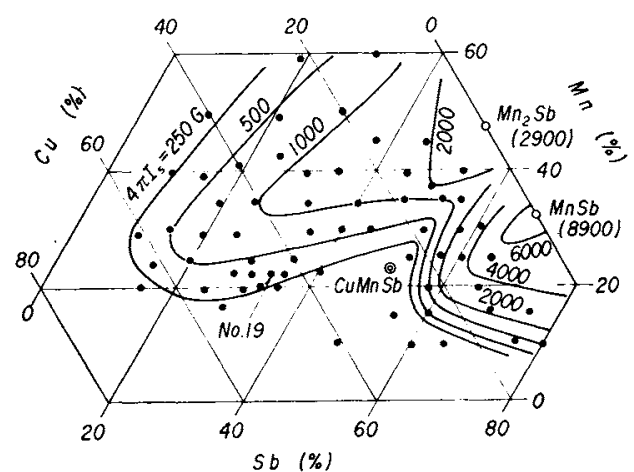

Fig.4 Highest saturation intrinsic magnetic flux density $4 \pi I_{s}$ in each of $\mathrm{Cu}-\mathrm{Mn}-\mathrm{Sb}$ alloys cooled at the rate of $100^{\circ} \mathrm{C} / \mathrm{hr}$ after heating at $550^{\circ} \sim 800^{\circ} \mathrm{C}$ for $5 \sim 50 \mathrm{hr}$ 
に示してめる。图中に記した黒点は测定した試料の組成 て, CuMnSb の化合物に相当する組成はの印, $\mathrm{Mn}_{2} \mathrm{Sb}$ と $\mathrm{MnSb}$ 化合物の組成はO印で示してある，図で見られるよ 弓急冷したままの $4 \pi I_{s}$ は $\mathrm{Mn}-\mathrm{Sb}$ 系の $\mathrm{Mn}_{2} \mathrm{Sb}$ あるいは MnSb KCuを添加するにしたがって次第に減少してゆく たけである，Fig.4 は合金を $550^{\circ} \sim 800^{\circ} \mathrm{C}$ の温度で $5 \sim 50$ hr 加熱した後, $100^{\circ} \mathrm{C} / \mathrm{hr}$ の速度で余冷却したときに得ら れた $4 \pi I_{s}$ のちの最高值をとり，濃度に対して統計的に 描かれた等值曲線を示す。四で見るように曲線の形状は大 体Fig.3 の場合に類似しておるが，強磁性の濃度範囲は Fig.3の場合に比し $\mathrm{Mn}_{2} \mathrm{Sb}$ 側において增加しており， $\mathrm{MnSb}$ 側で減少しておる.

つぎに Cu-Mn-Sb 系合金の保磁力を測定したが，まずそ の保磁力が熱処理によって如何に変化するかを知るため に, 代表的な 10 種類の合金について実験を行なったとこ ろ，溶融合金を銅型に鋳込んで急冷した後ささらにこれに 焼戻処理を施したときに，最す高い保磁力が得られること がかった、い例として合金 No.19について実験した 結果を示すと, Table 1 のと和りで，熱好理 1，(b)の昜合 には ${ }_{I} H_{C}$ が $2000 \mathrm{Oe}$ にも達しておる。よって $\mathrm{Cu}-\mathrm{Mn}-\mathrm{Sb}$ 合金の保磁力を求めるための試料の熱好理としてはもっぱ ら上記の方法を採用することにした。

Fig.5 は合金を銅型に鋳込んだ後， $150^{\circ} \sim 650^{\circ} \mathrm{C}$ の温度 において $30 \mathrm{~min} \sim 100 \mathrm{hr}$ 焼戻して得られた最高の ${ }_{I} H_{C} の$
るように， $\mathrm{Mn}_{2} \mathrm{Sb}$ 側の $I_{\boldsymbol{r}}$ は $\mathrm{Mn}-\mathrm{Sb}$ 合金に Cuを加える

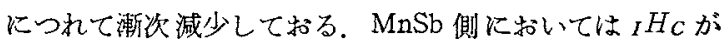

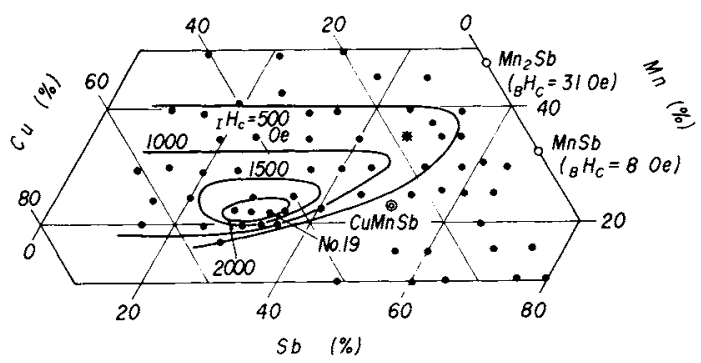

Fig. 5 Highest oercive force in each of $\mathrm{Cu}-\mathrm{Mn}-\mathrm{Sb}$ alloys tempered at $150^{\circ} \sim 650^{\circ} \mathrm{C}$ for $30 \mathrm{~min}$ $\sim 100 \mathrm{hr}$ after chill casting

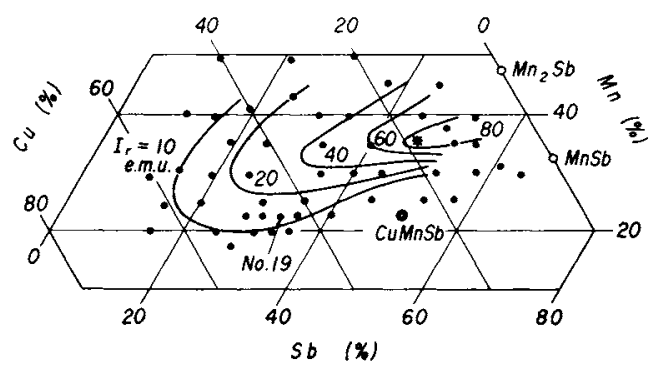

Fig.6 Residual intensity of magnetization $I_{r}$ corresponding to the highest coercive force in each of $\mathrm{Cu}-\mathrm{Mn}-\mathrm{Sb}$ alloy tempered at $150^{\circ} \sim$ $650^{\circ} \mathrm{C}$ for $30 \mathrm{~min} \sim 100 \mathrm{hr}$ after chill casting

Table 1 Effect of heat treatment on the magnetic properties of alloy No.19 $(22.04 \% \mathrm{Mn}-33.00 \%$ $\mathrm{Sb}$-rest $\mathrm{Cu}$ ). The coercive force after tempering is the highest value among those obtained by varying the tempering temperature and time

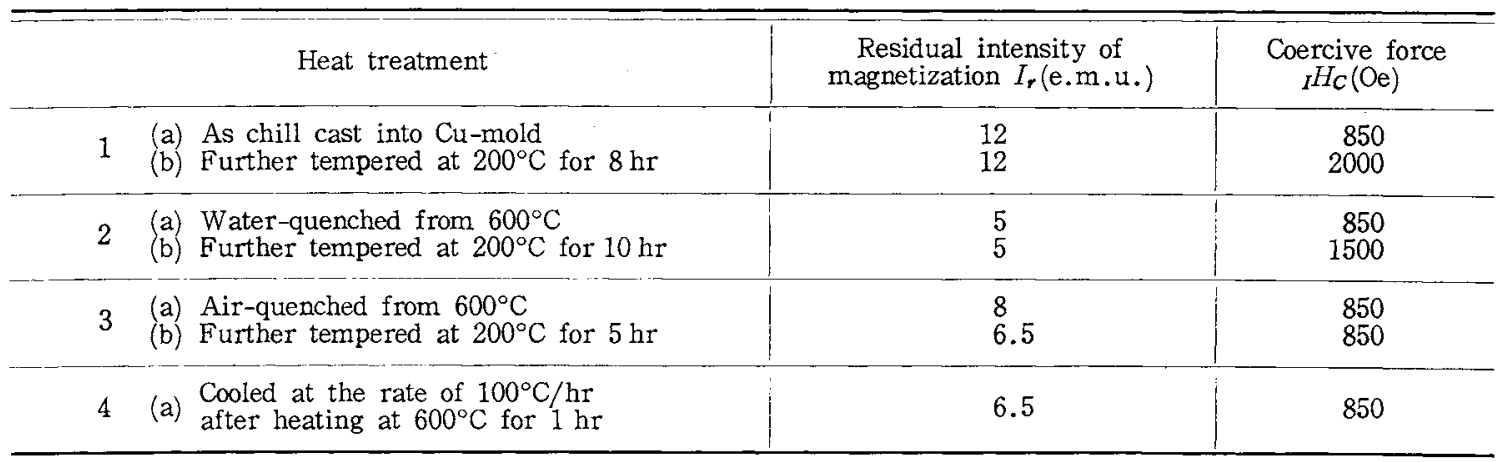

值を採り，濃度に対して統計的に描いた等值曲線を示吉。 図で見られるよ5に，IHCは Mn 約 17〜40\%, Sb 約 10〜 $54 \%$ 和よびCu約 9〜65\%の組成範囲に和いてかなり大き く，その最高值は合金 No. $19(22.04 \% \mathrm{Mn}-33.00 \% \mathrm{Sb}-$ rest Cu)の 2000 Oe にも就よんでおり，その上きのI Gである。な打大きな $I H_{C}$ の現われる組成範囲は $\mathrm{Mn}_{2} \mathrm{Sb}$ 化合物側に限られ， $\mathrm{MnSb}$ 化合物側では約 $50 \mathrm{Oe}$ 以下で非 常に小さい。园中の※印は最高の ${ }_{B} H_{C} 700$ Oe ${ }_{I} H_{C}=820$

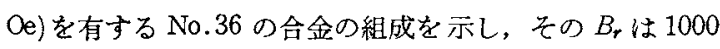
$\mathrm{G}\left(I_{r} \fallingdotseq 80 \mathrm{G}\right)$ である. Fig.6には各合金について得た最高 の ${ }_{I} H_{C}$ に相当する $I_{｝ \text { の等值曲線が示してある、図でかか }$
非常に小さいので，Irの等值曲線は図に描かなかった。 Fig.7 には最高の ${ }_{I} H_{C}$ を示す合金 No.19 について 銅型に 鋳込んだ後，種ふな温度と時間で尭戻しを行なったときの 磁性の変化が揭げてある. 図でわかるように合金 No.19の ${ }_{1} H_{C}$ は銅型に鋳込んだままの状態ですでに 850 Oe の高い 值を示し，これを加熱するといずれの温度においてすはじ め急激に増加し， $175^{\circ} \mathrm{C}$ 特よび $200^{\circ} \mathrm{C}$ の焼戻温度の場合に はそれぞれ6時間および8時間後一定の值に達する。しか し，温度が $225^{\circ} \mathrm{C}$ 以上になると $I_{C}$ は，ある焼戻時間に おいて極大に達した後減少する，Iは㜔戻時間ととるに， 一般にはじめ增加して一つの極大に達し，その後は減少す 
る。また I は低い温度の場合には変化が諗められないが， 高い温度の場合には単に減少するばかりである、つぎに Fig.8には最高の ${ }_{I} H_{C}$ を発揮した合金 No.19 と， ${ }_{I} H_{C}$ は 低いが比較的 $I_{r}$ の高い合金 No.36の減磁曲線が示してあ る.困で見るように No.19の ${ }_{I} H_{C}$ はかなり大きいが，そ の $I_{r}$ は僅かに $12 \mathrm{e} . \mathrm{m} . \mathrm{u}$.にすぎない. また, No.36の ${ }_{I} H_{C}$ は 820 Oeであるが,ての $I_{r}$ は $80 \mathrm{e} . \mathrm{m}$. u.で比較的大きい. つぎ合金No.19について，種々な熱処理を施してその 組織と結晶構造を検べた。むずはじめに銅型に鋳造したま まの状態, $600^{\circ} \mathrm{C} て ゙ 30 \mathrm{~min}$ 加熱したのら水焼入れした状

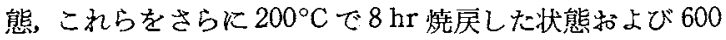
${ }^{\circ} \mathrm{C}$ で $30 \mathrm{~min}$ 加熱した後 $200^{\circ} \mathrm{C} / \mathrm{hr}$ の速度で徐冷した焼 鎍状態の合金について影微鏡試験を行なったところ，その 組織は互に非常に類似したものですった。ただ焼鈍状態の 組織だけは焼入れあるいは焼戻し状態のるのに此し非常に 粗大であった。つぎにこれら4状態の合金について，X線 解析を行なってその結晶構造を検べた，その結果，いずれ の場合にも強い $\mathrm{CuMnSb} \alpha \mathrm{cu}_{\mathrm{u}}$ の回折線のほかに弱い $\mathrm{Mn}_{2} \mathrm{Sb}$ の回折線が得られた。しかし $\mathrm{Mn}_{2} \mathrm{Sb} の$ 回折線だけ

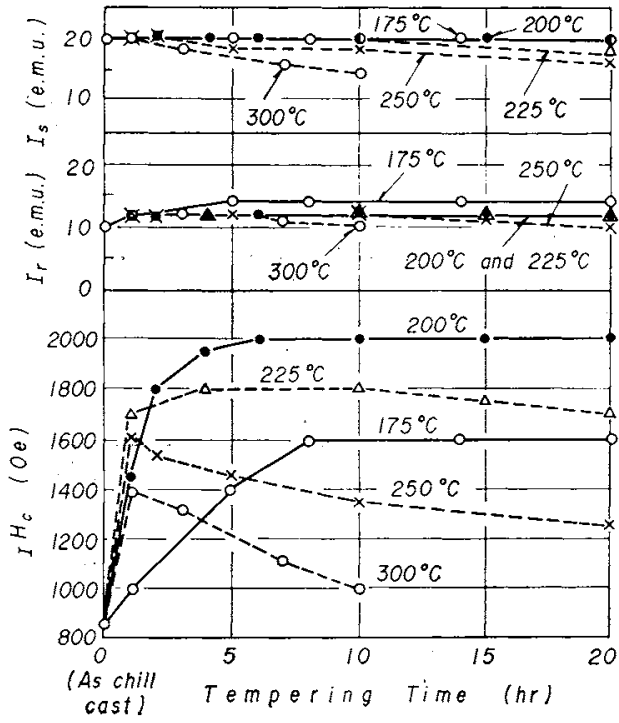

Fig.7 Effects of the tempering temperature and time on the magnetic properties of alloy No. $19(22.04 \% \mathrm{Mn}-33.00 \% \mathrm{Sb}-$ rest $\mathrm{Cu})$ chill cast

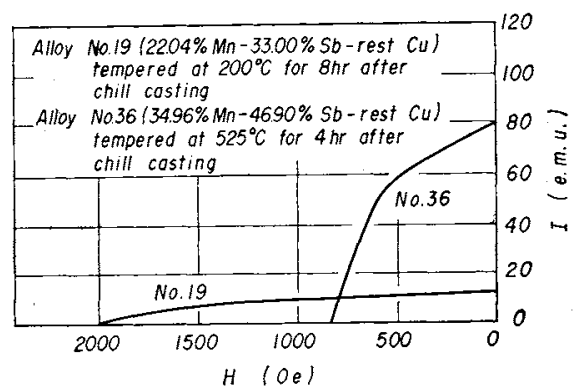

Fig. 8 Demagnetization curves of alloys No. 19 and No.36

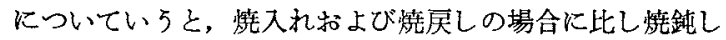
た場合の方か強かった。

いま一例として合金 No.19を銅型に鋳造したのち，200 ${ }^{\circ} \mathrm{C}$ の温度で $8 \mathrm{hr}$ 焼戻して最高の ${ }_{I} H_{C}$ を発揮させたとき の電子顕徽鏡写真を Photo.1 に示しておいた. この写真 の組織をX線解析の結果と照合して考えると，大きい円形 状の部分は初晶の常磁性 CuMnSb 化合物で, 小さい針状の 粒子は常磁性 $\alpha \mathrm{Cu}$ 固溶体中以分散して㔚るフェリ磁性の $\mathrm{Mn}_{2} \mathrm{Sb}$ 化合物であると推定される。

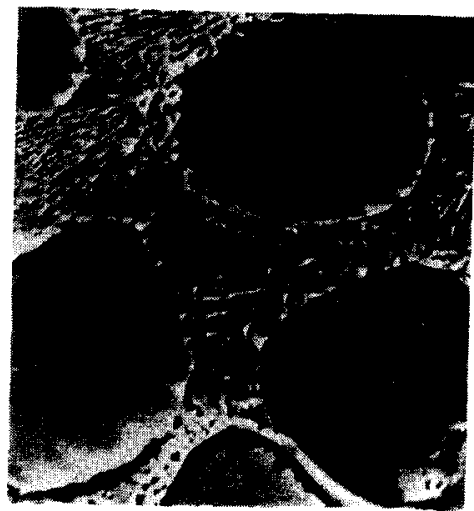

Photo.1 Electron micrograph of alloy No.19 tempered at $200^{\circ} \mathrm{C}$ for $8 \mathrm{hr}$ after chill casting.(Large circular regions primary precipitates of $\mathrm{CuMnSb}$ compound: Small acicular particles- $\mathrm{Mn}_{2} \mathrm{Sb}$ compound dispersed in $\alpha$ cu solid solution) $(\times 6000 \times 5 / 6)$

な执参考のために Fig.9に合金 No.19について磁気天 科により約 $300^{\circ} \mathrm{C} / \mathrm{hr}$ の速度で加熱および冷却して湘定し た磁性の変化を示しておいた，図でわかるよ5に，銅型に 鋳込んだものは加熱寸ると $110^{\circ} \sim 135^{\circ} \mathrm{C}$ の温度に抏いて 磁化の急な増加を示し，その後は温度とともに磁気変態点 の約 $275^{\circ} \mathrm{C}$ まで単調に低下する.つふいて温度を $550^{\circ} \mathrm{C}$ ま で上げて $30 \mathrm{~min}$ 加熱したのち冷却すると，磁気変熊点は 約 $225^{\circ} \mathrm{C}$ に下がり,さらに再加熱を行ならと, $300^{\circ} \mathrm{C}$ に上 昇する.つまり磁化対温度曲線は非可逆的であることる示 しておる.

以上の結果から， $\mathrm{Cu}-\mathrm{Mn}-\mathrm{Sb}$ 系合金に括ける高保磁力の

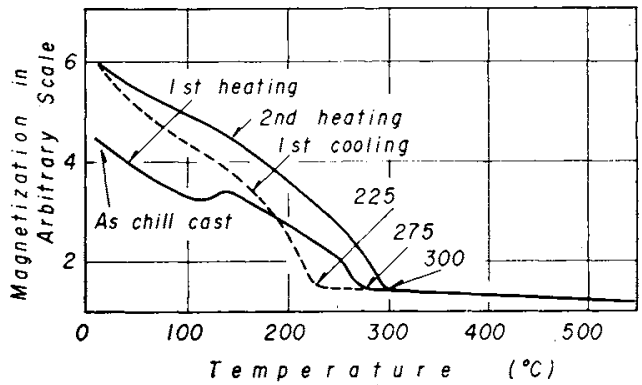

Fig.9 Magnetic analysis of alloy No.19(22.04\% $\mathrm{Mn}-33.00 \% \mathrm{Sb}-$ rest $\mathrm{Cu}$ ) 
原因は，非磁性 CuMnSb 扣よび非磁性 $\alpha \mathrm{cu}$ 相の地にフェ リ磁性 $\mathrm{Mn}_{2} \mathrm{Sb}$ の微細な針状粒子が分散して存在し，その ため粒子が単磁区的になって，大きな結晶磁気異方性エネ ルギーならびに形状磁気暴方性エネルギーを生ずることに あると考它られる。

\section{IV. 括}

Mn 4.98〜59.80\%および Sb 10.03〜79.71\%を含む 68 種類の $\mathrm{Cu}-\mathrm{Mn}-\mathrm{Sb}$ 系合金について急冷却, 焼戻しおよび 狫鈍処理を施し，その磁性を测定し，結晶構造解析を行な って,つぎの結果を得た。

（1）銅型に鋳造したままの急冷状態における合金の $4 \pi I_{s}$ は $\mathrm{Mn}-\mathrm{Sb}$ 系のフェり磁性 $\mathrm{Mn}_{2} \mathrm{Sb}$ るるいは強磁性 $\mathrm{MnSb}$ に Cu を添加するにしたがって次第に減少してゆく だけである。

(2) 各合金につき $550^{\circ} \sim 800^{\circ} \mathrm{C}$ の温度で $5 \sim 50 \mathrm{hr}$ 加熱 した後, $100^{\circ} \mathrm{C} / \mathrm{hr}$ の速度で徐冷して得られた最高の $4 \pi I_{s}$ は, 合金の組成に対して急冷状態の場合と類似の変化を示
すが, $\mathrm{Mn}_{2} \mathrm{Sb}$ 側の組成に括いては急冷状態の場合に比し強 磁性の濃度䉒囲之 $4 \pi I_{s}$ の值が大きく， $\mathrm{MnSb}$ 側の組成で は小さい。

（3）合金を銅型に鋳込んだ後， $150^{\circ} \sim 650^{\circ} \mathrm{C}$ の温度にお。 いて $30 \mathrm{~min} \sim 100 \mathrm{hr}$ 焼戻して得られた各合金の最高の ${ }_{I} H_{C}$ は, $\mathrm{Mn}$ 約 17 40\%, Sb 約 10〜54\% および $\mathrm{Cu}$ 約 9 $\sim 65 \% の \mathrm{Mn}_{2} \mathrm{Sb}$ 側に和ける組成筙囲に括いてかなり大き く，その最高の ${ }_{I} H_{C}$ は $\mathrm{Mn} 22.04 \%, \mathrm{Sb} 33.00 \%$ および残 余Cu から成る合金の $2000 \mathrm{Oe}$ で，そのI

(4) Cu-Mn-Sb 系合金の高保磁力の原因は，主として非 磁性の CuMnSb 化合物と非磁性 $\alpha_{\mathrm{Cu}}$ 相の地に，フ二リ磁 性 $\mathrm{Mn}_{2} \mathrm{Sb}$ の単磁区的な政細粒子が分散して存在し，それ によって大きな結晶磁気異方性エネルギーと形状猫気異方 性エネルギーが生ずることにめるものと考えられる。

終りに㐫たり，実験装置使用の便宜を与兄られた東北大 学工学部金子秀夫教授, 本間基文助教授ならびに分析の労 をとられた東北特殊銅株式会社分析課の方々に対乙深く感 謝の意を表する。 